OPEN ACCESS

Edited by:

Zsolt J. Balogh,

The University of Newcastle, Australia

Reviewed by:

Feza Korkusuz,

Hacettepe University, Turkey

Seth Michael Tarrant,

Hunter New England Health, Australia

${ }^{*}$ Correspondence:

Meir Marmor

meir.marmor@ucsf.edu

Specialty section:

This article was submitted to

Orthopedic Surgery,

a section of the journal

Frontiers in Surgery

Received: 29 July 2020

Accepted: 12 October 2020

Published: 12 November 2020

Citation:

Marmor M, El Naga AN, Barker J, Matz J, Stergiadou S and Miclau T (2020) Management of Pelvic Ring Injury Patients With Hemodynamic Instability. Front. Surg. 7:588845 doi: 10.3389/fsurg.2020.588845

\section{Management of Pelvic Ring Injury Patients With Hemodynamic Instability}

\author{
Meir Marmor ${ }^{1 *}$, Ashraf N. El Naga ${ }^{1}$, Jordan Barker ${ }^{1}$, Jacob Matz ${ }^{1}$, Styliani Stergiadou ${ }^{2}$ \\ and Theodore Miclau ${ }^{1}$ \\ ${ }^{1}$ Department of Orthopedic Surgery, University of California, San Francisco, San Francisco, CA, United States, ${ }^{2}$ Faculty of \\ Medicine, University of Thessaly, Larissa, Greece
}

Pelvic ring injuries (PRI) are among the most difficult injuries to deal with in orthopedic trauma. When these injuries are accompanied by hemodynamic instability their management becomes significantly more complex. A methodical assessment and expeditious triage are required for these patients followed by adequate resuscitation. A major triage decision is whether these patients should undergo arterial embolization in the angiography suit or prompt packing and pelvic stabilization in the operating room. Patient characteristics, fracture type and injury characteristics are taken into consideration in the decision-making process. In this review we discuss the acute evaluation, triage and management of PRIs associated with hemodynamic instability. An evidence based and protocol driven approach is necessary in order to achieve optimal outcomes in these patients.

\section{Keywords: pelvic fracture, hemodynamic instability, angioembolization, pre-peritoneal pelvic packing, bleeding,} triage, resuscitation, shock

\section{INTRODUCTION}

Pelvic ring injuries (PRIs) with hemodynamic instability typically occur in polytrauma patients. The initial assessment of the polytrauma patient follows the Advanced Trauma Life Support (ATLS) guidelines (1), which call for evaluation and treatment of airway and breathing problems first and then assessment and treatment of hemodynamic instability (HI). The ATLS guidelines define $\mathrm{HI}$ as having a blood pressure $<90 \mathrm{mmHg}$ and heart rate $>120 \mathrm{bpm}$, with evidence of skin vasoconstriction (cool, clammy, and decreased capillary refill), altered level of consciousness, and/or shortness of breath (1). Other definitions include having a systolic blood pressure (SBP) of $>90 \mathrm{mmHg}$ but requiring at least 4-6 units of packed red blood cells within the first $24 \mathrm{~h}$, vasopressor drugs $(2,3)$, and/or have an admission base deficit $(\mathrm{BD})>6 \mathrm{mmol} / \mathrm{L}$ and/or a shock index (heart rate divided by SBP) $>1(4,5)$. In the setting of trauma, $\mathrm{HI}$ is always assumed to be the result of active bleeding or significant blood loss prior to hospital arrival. The pelvic ring, if broken, can be a major contributor to $\mathrm{HI}$ and therefore the expeditious evaluation and treatment of pelvic bleeding is a crucial part of managing trauma patients with $\mathrm{HI}$.

\section{INITIAL ASSESSMENT AND TRIAGE}

\section{Physical and Laboratory Examination}

$\mathrm{HI}$ is diagnosed during the initial physical examination, also known as the ATLS primary survey, which also attempts to identify whether significant bleeding exists in the head, chest, abdomen, 
or extremities (1). The initial pelvis exam includes urethral, perineal, rectal, and vaginal exams as well as a general assessment of mechanical stability (6). Mechanical stability is assessed by manual compression of the iliac wings and/or greater trochanters. Distraction should be avoided due to the possibility of increasing pelvic volume and allowing further bleeding (1). Pelvic compression should be done one time only, by a senior member of the trauma team, to limit the risk of disrupting an existing blood clot (1). Other physical exam findings that suggest pelvic fracture include evidence of ruptured urethra (scrotal hematoma or blood at the urethral meatus), discrepancy in limb length, and rotational deformity of a leg without obvious lower extremity fracture. At the conclusion of the primary survey, it is imperative to cover the patient with warmed blankets to help prevent hypothermia. Laboratory-tests are typically obtained during the primary survey. Sensitive laboratory markers of acute traumatic hemorrhage include serum lactate, base deficit, and gastric intramucosal $\mathrm{pH}$, which have been shown to be more reliable indicators of $\mathrm{HI}$ than hemoglobin level and hematocrit $(7,8)$.

\section{Imaging and Injury Classification}

A standard anteroposterior (AP) pelvic $\mathrm{X}$-ray (PXR) as part of the ATLS protocol can help to quickly identify life-threatening PRIs and guide triage (9-12). Chest bleeding is assessed using a chest $\mathrm{x}$-ray (CXR) and abdominal bleeding with a focused assessment with sonography for trauma (FAST) exam of the abdomen (1). Classification of pelvic fractures can be accurately done from the PXR alone (13). The two most common classifications used for pelvic fractures are the Tile classification (14) and the Young and Burgess classification (15). A more recent scheme was proposed in 2018 by the AO/OTA (16). The Tile classification is focused on biomechanical stability of the sacroiliac complex (14), whereas the Young and Burgess classification is focused on mechanism of injury and has also been associated with degree of blood loss (15). Lateral compression mechanism (LC) fractures with increasing involvement, 1-3, exhibit an increased incidence of pelvic vascular injury, retroperitoneal hematoma, shock, and 24$\mathrm{h}$ volume needs (17). Anteroposterior compression (APC), types $1-3$, exhibit an increased incidence of injury to spleen, liver, bowel, pelvic vascular injury with retroperitoneal hematoma, shock, sepsis, and ARDS, and large increases in volume needs, with incidence of brain and lung injuries in all grades. The pattern of injury in APC3 was correlated with the greatest 24$\mathrm{h}$ fluid requirements and with a rise in mortality as the APC grade rose (17). The vertical sheer (VS) mechanism, despite being highly unstable mechanically, has more recently been shown to have very low transfusion requirements (18-22). A suggested explanation is that fracture types such as VS and LC1 involve shortening of the vascular structures $(21,22)$, whereas LC3, APC2, and APC3 fractures involve stretching and tearing of the veins and arteries adjacent to the posterior pelvic ring (2123). Fracture displacement in proximity to major arteries are associated with the highest risk for arterial injury (24). These locations include vertically displaced fractures in the middle part of the superior pubic ramus, the area along the internal surface of the ischial ramus, and the inferior pubic ramus, as well as in the apex of the greater sciatic notch and around the ventral part of the sacroiliac joint (24). A pelvic computed tomographic (CT) scan can allow more precise classification as well as assessment of the size of a pelvic fracture hematoma (25). CT hemorrhage volumes exceeding $500 \mathrm{ml}$ have a $45 \%$ rate of pelvic arterial injury compared to $5 \%$ in volumes below $200 \mathrm{ml}$ (26). A pelvic hematoma of $>3.35 \mathrm{~cm}$ in size is correlated to an increased need for angiography and increased mortality (27). The presence of intravenous contrast extravasation on a CT scan, often called a "blush," indicates vascular disruption and active arterial bleeding (either contained or free) (28-30). A triple-phase contrast-enhanced CT consists of an arterial phase, a portal phase, and a delayed phase $(31,32)$. A blush on the arterial phase indicates active arterial bleeding; it can be seen as a hyperdensity within a hematoma. A delayed phase may show injuries to urologic structures. Presence of a blush is not an absolute indication for an operative or angiographic intervention $(28,29)$, and because of hypotension or arterial spasm, in the absence of a blush it cannot be assumed that there is no active bleeding (30). Furthermore, bleeding from the marrow of the fractured bone can lead to significant HI (33).

\section{The Pelvic Binder}

A pelvic binder $(\mathrm{PB})$ is a device used to compress the fractured pelvis in an effort to stop bleeding (1). PBs can improve hemodynamic stability and therefore should be applied as soon as the patient with $\mathrm{HI}$ is suspected of having a PRI. The PB can be applied when first seeing the patient in the field or in the ambulance as pelvic bleeding can cause HI very rapidly. Use of $\mathrm{PBs}$ is associated with significant reduction in transfusion requirements $(34,35)$, as well as shorter intensive care duration and shorter hospital stay (36). There are no contraindications to applying a $\mathrm{PB}$ on a suspected PRI. The sheet or binder is applied at the level of the greater trochanters, never around the abdomen or waist, and should be flat against the skin to maximize surface area. Sheets should be secured with clamps to avoid undue pressure from knots $(37,38)$. An appropriately placed binder and sheet should allow for groin or abdominal access as holes can be cut out to provide access $(34,39)$. The best results of external pelvic stabilization are achieved in rotationally unstable LC fracture type III and APC types II and III $(40,41)$. With additional vertical instability (VS or CM type injury), stabilization can be achieved in only $27 \%$ of cases and supplementary ipsilateral skeletal traction is needed $(40,41)$. There have been concerns that a pelvic binder may produce secondary displacement of a lateral compression (LC) fracture causing further damage. A small increase in internal rotation and reduction of pelvic inlet area in unstable LC type II fracture has been reported with the application of a binder in cadaveric studies (42). However, there are no case reports in the literature of binder application causing damage or significant displacement in lateral compression injuries (43). Furthermore, the degree of displacement of the pelvic ring is likely to be far greater at the time of injury than afterwards with the application of a binder. Therefore, PB can be used in all LC fractures (43). Pelvic binder use should be limited to $24-48 \mathrm{~h}$. Risk of complications such as 
skin necrosis and pressure ulcerations increase by continuous application of a pressure above $9.3 \mathrm{kPa}$ for more than $2-3 \mathrm{~h}$ (44).

\section{Triage}

Diagnostic workup strategies in the emergency room must be standardized and streamlined in order to avoid an unnecessary delay to definitive bleeding control (45). Provided that the patient has HI and a mechanically unstable pelvis on PXR, the first triage decision is whether a patient is stable enough to go to the CT scanner (Figure 1). As soon as the patient is hemodynamic stable then CT of abdomen and pelvis with contrast should be used in order to detect major bleeding. The second triage decision is whether to take the patient to the operating room, the angiography suite, or the intensive care unit. If the patient is responsive to resuscitation and has evidence of arterial bleeding on CT then angiography and arterial embolization for hemodynamic stability are the next step, followed by mechanical stabilization (either internal fixation or external fixation) of the pelvis in the operating room (OR). If the patient has $\mathrm{HI}$ and is unresponsive to resuscitation efforts then the patient should undergo a FAST exam in the trauma bay and then go to the OR for laparotomy (positive FAST) or mechanical stabilization and pelvic packing (negative FAST or retroperitoneal bleeding identified during laparotomy). This is then followed by CT scan and either angiography or ICU based on CT results (46). A subject of more controversy is where to send the patient that has HI and a mechanically unstable pelvis but does not have arterial bleeding on CT or has evidence of arterial bleeding but is responsive to initial resuscitation. Proponents of angiography and embolization first (47) or mechanical stabilization first (48) exist. Regardless, resuscitation efforts should continue, uninterrupted, in these patients.

\section{RESUSCITATION}

The initial management of the patients with hemodynamically unstable PRIs revolves around patient resuscitation. Over the past few decades there has been a greater appreciation for the physiologic disequilibrium that follows acute trauma. The classic "lethal triad" included a combination of hypothermia, coagulopathy, and acidosis, each of which furthered a patient's physiology away from normal and are associated with poor outcomes (49-51). Over the past decades, a "two hits" model of systemic inflammatory response in the critically injured patient has been described (52). The initial trauma acted as the first hit that leads to the initiation of an immune-inflammatory response with potential interventions done during this period such as surgical interventions being a potential "second hit" driving a patient toward a more systemic inflammatory response characterized by organ dysfunction and is a cause for later morbidity and mortality following acute trauma. The immunological activation and response to inflammation have a genetic background. An intervention done during this period such as surgical interventions consist a potential "second hit" driving a patient toward a more systemic inflammatory response characterized by organ dysfunction and is a cause for later morbidity and mortality following acute trauma. The concept of the second hit has now been superseded by the concept of the "genomic storm" in which up to $80 \%$ of the leukocyte transcriptome is altered together with suppression of genes involved in adaptive immunity (53). Efforts to prevent this socalled "second hit" has led to the development of damage control resuscitation (52).

Damage control resuscitation refers to an overall staged approach to care for the critically or multiply injured patients rather than a specific intervention $(52,54)$. Damage control resuscitation was initially described in penetrating abdominal trauma but the concept was subsequently extended to skeletal trauma as well including PRIs $(52,55,56)$. The primary goal of damage control is perform life-saving interventions while minimizing the initial surgical burden to allow for restoration of a patient's physiology so as to minimize the burden of the "second hit." Thus, the initial focus is on treating blood loss, addressing coagulopathy, and correcting acidosis. Early studies that demonstrated pulmonary and systemic benefits by early definitive fixation of femur fractures led to the concept of "Early Total Care." The increased understanding of the physiology of the trauma patient and the need to avoid the "second hit" led to DCS. Most recently, the concept of Early Appropriate Care (EAC) has been introduced. With EAC the patients are taken to definitive fixation of their fractures as soon as they are considered resuscitated by physiological parameters and laboratory findings (57). Identification and temporizing measures for PRI associated blood loss are discussed in other sections of this paper.

In terms of restoring blood volume, high volume crystalloid solutions were historically used for fluid resuscitation. In exsanguinating patients, aggressive, and early resuscitation with blood products has been associated with increased survival rates (58-61). The increased recognition of the role of coagulopathy in disrupting a patient's physiology and worsening outcomes raises concerns that crystalloid based resuscitation contributes through dilutional coagulopathy and possibly via the disruption of pre-mature blood clots in areas of injury leading to further blood loss $(50,51)$. Given these concerns there has been an increasing adoption of early blood product administration. While management of coagulopathy was historically an afterthought after a patient received large blood volumes, there is increased recognition of the benefit of transfusing mixtures of packed red blood cells, platelets, and fresh frozen plasma. Though there has been much written on the optimal ratios of products to use in specific scenarios and patient populations, early product transfusion is now the mainstay for the treatment of acute traumatic blood loss and coagulopathy $(49,60,62,63)$. Further, permissive hypotension has been advocated for resuscitating patients such that end organ perfusion is maintained while minimizing hydrostatic clot disruption with a goal SBP between 80 and $90 \mathrm{mmHg}(52,54)$. Vasopressors are typically reserved either only when SBP goals cannot be maintained despite the initial fluid expansion or if there are mean arterial pressure goals such as maintaining cerebral perfusion pressure in patients with head injuries or in the case of spinal cord injuries (64). 


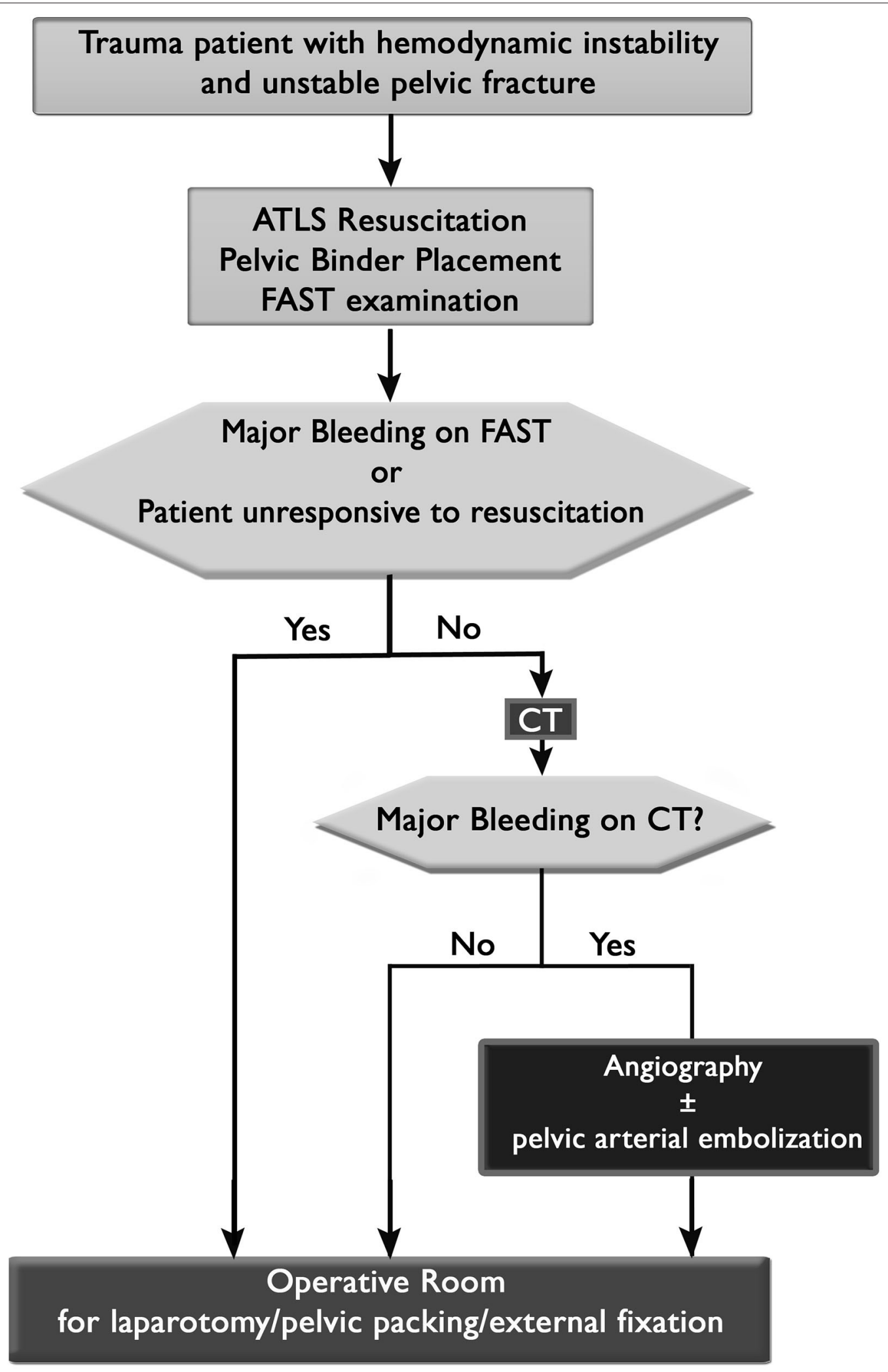

FIGURE 1 | Triage algorithm for patients with hemodynamic instability and unstable pelvic ring injuries. 
Coagulopathy is associated with increased bleeding, organ dysfunction, and mortality and must be addressed (49, 6567). This is secondary to clotting component consumption, hemodilution, component loss in the setting of hemorrhage, and component dysfunction in the setting of acidosis and hypothermia. Recognition of this has driven the increasing incorporation of factor transfusion in the resuscitative process. In addition to the common measures of coagulopathy (e.g., PT and PTT), there have been recent advances in laboratory medicine such as thromboelastography or rotational thromboelastometry which seek to identify whether a coagulopathy can be attributed to platelet function, clotting strength, or fibrinolysis and thereby guide treatment in polytrauma patients with PRIs (68-71). However, such methods are not yet widely available (54).

With regards to acidosis correction, the mainstay is to address the above issues by addressing ongoing blood loss and end organ perfusion $(52,72)$. Pharmacologic agents to correct acidosis have not been shown to offer much advantage (72). However, measures of acidosis such as a lactate or base deficit are very useful as a measure of a patient's overall response to resuscitative measures.

\section{PELVIC ARTERIAL EMBOLIZATION AND PELVIC PACKING}

After initial assessment, binder placement, and resuscitation, hemodynamic status is reassessed to determine whether the patient is responding to treatment. If hypotension persists, the decision must then be made of whether the patient is sufficiently stable for angiographic embolization in the interventional radiology suite or pelvic packing in the operating room.

It has been estimated by (73) in a study of 27 post-mortem angiographies that only $11.1 \%$ of patients with pelvic fractures exhibit arterial bleeding. Otherwise, bleeding is primarily attributed to veins and fractured cancellous edges. The ideal indication for angiography is arterial hemorrhage, yet discerning the source of hemorrhage is not a simple task. In a prospective multi-center observational study of 1,339 patients with pelvic fractures conducted by the American Association for the Surgery of Trauma, Costantini et al. (74) reported little consensus among 11 level one trauma centers regarding management of hemorrhage in the setting of pelvic fracture. Their cohort included 178 patients admitted in shock (defined as SBP < $90 \mathrm{mmHg}$, HR > $120 \mathrm{bpm}$, or base deficit > -5), of which $18.5 \%$ were initially treated with pelvic binder, $24.7 \%$ went for diagnostic angiography (68.2\% of whom were embolized), $9.6 \%$ were treated in an external fixator alone, 5.1\% underwent preperitoneal packing alone, 5.1\% underwent external fixator plus embolization, $1.7 \%$ external fixator plus pre-peritoneal packing, and $68 \%$ no pelvic intervention. Mortality in this series was $32 \%$ for patients with pelvic fracture presenting in shock (74). In a nationwide survey of 40 trauma medical directors in the US, $33 \%$ perceived pelvic packing as effective, $72 \%$ perceived pelvic packing as safe, and $76 \%$ reported that packing was utilized as the third or fourth priority in their treatment algorithm. Geographic trends were seen with regard to utilization (75).

\section{Angiographic Embolization}

The first published report of pelvic angiography in the setting of pelvic fractures was in a 1971 editorial by Athanasoulis et al. (76) from Boston City Hospital, commenting on the possible utility of initial venography and subsequent arteriography as a diagnostic tool to identify the location of bleeding in the pelvis. A small series of therapeutic embolization was published 1 year later by Margolies et al. (77) at Massachusetts General Hospital, who selectively catheterized a branch of the internal iliac artery to localize the site of bleeding, followed by embolization using autologous clotted blood. This was a particularly attractive option given the alternatives at the time, which included ligation of the internal iliac artery, a practice met with little success given the large number of collateral vessels in the pelvis (78).

The common iliac arteries bifurcate from the aorta around the L4 spinal level, continuing into the pelvis before branching into the internal and external iliac arteries. The external iliac arteries continue over the pelvic brim as the common femoral arteries, and the internal iliac arteries supply the majority of the pelvis via multiple named branches. These include the superior gluteal, inferior gluteal, iliolumbar, lateral sacral, umbilical, obturator, internal pudendal, middle rectal, uterine (in females), and superior vesical branches. Embolization can be selective, which targets a specific branch of the internal iliac artery, or non-selective, which plugs the arterial leak upstream at the internal iliac artery. Selective embolization is preferred when possible, though the indication to non-selectively embolize may be appropriate in the setting of a hemodynamically unstable patient. The vessels most commonly embolized are, in descending frequency, the internal iliac (67.2\%), unnamed branches of the internal iliac (17\%), superior gluteal artery (4.4\%), obturator artery (4.1\%), and internal pudendal artery (3.2\%) (79). Embolization can be executed with various media, including coils, gelfoam pledgets, vascular plugs, particles, liquid embolics, or a combination of these (80), with coils and gelfoam being the most commonly employed in the authors' experience. Coils work by inducing thrombosis, often enhanced by Dacron wool tails, not mechanical occlusion. They are permanent devices and are effective in proximal embolization. Gelfoam is a water soluble temporary embolic agent that is completely resorbed within 2-3 weeks (80).

Time from injury to intervention has been shown to make a notable difference in outcome. Agolini et al. (81) reviewed 806 patients with pelvic fractures from a single institution and found that $4.3 \%$ of them underwent angiography, and $1.9 \%$ underwent embolization. Patients embolized within $3 \mathrm{~h}$ had a mortality rate of $14 \%$, compared to $75 \%$ in those embolized after $3 \mathrm{~h}$ (81). Tanizaki et al. (74) analyzed 140 patients with pelvic fractures, 24 of which were hemodynamically unstable. Patients who underwent embolization within $60 \mathrm{~min}$ of arrival had a mortality rate of $16 \%$ compared to $64 \%$ in those over $60 \mathrm{~min}$ (47).

Repeat embolization may be required in select patients. Fang et al. (82) reviewed 140 patients with pelvic fractures 
who underwent embolization for suspected arterial hemorrhage, $19 \%$ of which required repeat embolization. Predictors for repeat embolization in their series were initial hemoglobin $<7.5$, superselective embolization at the time of the initial procedure, and $>6$ units of transfused red blood cells after initial embolization. The source of bleeding occurred at a new site in $38 \%$ of patients. The authors recommended maintaining the sheath in the femoral artery for $72 \mathrm{~h}$ should the need for repeat angiography and embolization arise (82).

Complications of diagnostic angiography include contrast mediated kidney injury, allergic reaction, and cannulation site morbidity. Complications of embolization include subsequent surgical wound breakdown, deep infection, gluteal muscle necrosis, nerve injury, bladder or ureteral infarction, bowel infarction, claudication, and impotence. Reported complication rates range from 3 to $35 \%$, though the deleterious impact of the traumatic event itself is likely a confounding variable (79, 83-85). Non-selective embolization of the internal iliac artery, particularly bilaterally, may lead to higher complication rates (84), though this point has been contested in the literature $(86,87)$. Such a technique should be considered with caution, though hemodynamic instability in select settings may be an appropriate indication.

Mortality rates are likewise multifactorial, making reports of angioembolization difficult to interpret. Among patients with pelvic fractures presenting in shock treated primarily with angioembolization, mortality rates range from 12 to $40 \%(83,87-93)$.

\section{Pelvic Packing}

Vague reports make it difficult to discern the origin of pelvic packing, though mention is made by Quinby in a 1971 editorial, alluding to its inefficacy in a mechanically unstable PRI because "there is little in the way of stable platforms to pack against" (94). The first complete description of packing was by Pohlemann and Tscherne in Hannover Germany in a technique paper published in 1995 (95).

Drawing from their observations in Europe, Cothren et al. published a technique in 2007 shown to be effective in a large series. Making a $6-8 \mathrm{~cm}$ vertical skin incision starting just above the pubic symphysis, dissection is taken carefully through the rectus sheath. The fracture hematoma often dissects the preperitoneal space (of Retzius) beforehand, but this can be done bluntly with a finger. Blunt dissection continues in the paravesical space back to the presacral region, and three laparotomy sponges are placed. The same steps are repeated for the contralateral side. Closure includes reapproximation of the rectus sheath with 0 PDS suture and skin staples. If a laparotomy is performed, it may be done so through a separate incision placed cranially to separate the two wounds. An added benefit of this technique is that multiple teams can work concurrently $(96,97)$.

The abdominopelvic cavity wall is made up of seven distinct tissue planes, forming a histological palindrome. From superficial to deep, they include the skin, subcutaneous fatty tissue, external muscle fascia, muscle layer(s), internal muscle fascia, extraperitoneal fatty tissue, and peritoneum. The abdominopelvic viscera, including the bladder, kidneys, ureters, and major vessels, are found within the extraperitoneal fatty layer, and it is primarily this expansive layer that fills with blood during pelvic fractures, and this selfsame layer into which packs are placed.

Intuitively, similar to angioembolization, timing of pelvic packing is thought to play a significant role in outcomes, though comparative studies are lacking. Burlew et al. (97) reported their mean time from admission to the operating room as $44 \mathrm{~min}$ with $21 \%$ mortality rates. The authors are not aware of a series comparing outcomes as a function of time (97).

Burlew et al. have published one of largest recent series utilizing a pre-peritoneal packing protocol over 11 years, including 128 patients with pelvic fractures presenting with persistent SBP $<90 \mathrm{mmHg}$ after placement of a binder or sheet and 2 units of pRBC. Mean ISS was 48 and 18 of the fractures were open. Twenty-seven percent of patients underwent diagnostic angiography after pre-peritoneal packing given concern for continued bleeding, $46 \%$ of whom went on to embolization. Twelve percent of patients in this series experienced pelvic space infection, and the mortality rate was $21 \%$ (97).

Few comparative studies have been published of angioembolization and pelvic packing. In a retrospective single-institution series of 40 hemodynamically unstable patients with pelvic fractures, Osborn et al. (98) compared 20 patients who underwent pre-peritoneal packing (mean time from admission $45 \mathrm{~min}$ ) with 20 patients who underwent angioembolization (mean time from admission $130 \mathrm{~min}$ ). In those who underwent pre-peritoneal packing, four died, none of which due to hemorrhage, compared to six deaths in the angioembolization group, two from acute hemorrhage (98).

Li et al. (99) conducted a quasi-randomized controlled trial of hemodynamically unstable PRI patients, 29 of whom were randomized into a pelvic packing group, and 27 of whom were randomized into an angiography group. Of those who underwent packing, ISS was 48 , time to surgery was $77 \mathrm{~min}$, operative time was $60 \mathrm{~min}$, and 4 patients died (none from hemorrhage). Of those who underwent angiography, ISS was 43 , time to intervention was $102 \mathrm{~min}$, procedure time was $84 \mathrm{~min}$, and 5 patients died (two from exsanguination) $(98,99)$.

\section{EXTERNAL FIXATION}

In patients with hemodynamic instability following PRI, mechanically stabilizing the osseous structures and reducing pelvic volume are important means to prevent further bleeding. In the emergency setting, these goals need to be achieved without excessive technical complexity or time-consuming interventions.

The pelvic binder remains the default non-invasive method for rapid temporary stabilization of the pelvis. In fact, when compared to an external fixator, there were no significant differences in stability conferred by an external fixator vs. a pelvic binder for unstable pelvic injuries (100). The shortcoming of a pelvic binder are soft tissue complications secondary to the pressure that is applied $(34,37,101)$, in addition to reduced access to the abdomen, pelvis, and groin areas, as well as decreased ability to deal with associated injuries involving the hip and lower 
extremities. Additionally, a binder is temporary and not a means for definitive treatment of a PRI.

These issues are overcome by external fixation of the pelvis, which provides mechanical stability and can serve as a temporizing measure or as definitive treatment. The efficacy of early application of external fixators has been previously demonstrated, with endpoints of decreased morbidity, decreased transfusion requirements, and improved mortality $(19,95,102$, 103). External fixators are applied in a percutaneous manner and function well to provide fracture stabilization, tamponade expanding hematoma, and reduce hemorrhage from fracture sites. In patients that undergo pre-peritoneal pelvic packing, application of external fixation is necessary as a means to provide counter pressure for effective pelvic packing $(98,104,105)$. External fixation should also ideally precede laparotomy as a means to prevent the disruption of the tension band created by the abdominal wall on the iliac wings $(103,106)$.

The type of PRI dictates the appropriate external fixation construct. Other considerations are patient body habitus, available imaging, and surgeon experience (107). Anterior external fixation constructs are most appropriate for APC and LC-type injuries and work particularly well when the posterior ligaments are intact (107). The anterior external fixator can be placed with pins in the iliac crests, in the supra-acetabular region, or less commonly, in the subcristal area. Placement of pins in the iliac crests can be done in the emergency department, with or without fluoroscopy, and is likely the fastest option. Biomechanically, supra acetabular pins are advantageous due to stronger bone in the sciatic buttress and a better vector for pelvic ring closure $(40,107)$. In both constructs, when correctly assembled, access to the abdomen can be unimpeded (108). Disadvantages of external fixation include poor patient tolerance, pin site infection, and aseptic loosening (109).

In posterior pelvic ring disruptions, an anteriorly based fixator is ineffective in delivering posterior compression (110). This can be improved by using a femoral distractor as a compressor or by modifying the anterior frame into an $\mathrm{X}$ configuration ( $\mathrm{X}$ frame) $(110,111)$. Nonetheless, in injuries involving significant posterior diastasis, the posteriorly based pelvic $\mathrm{C}$ clamp is more effective $(112,113)$. The C clamp consists of two sidearms connected by a crossbar and is meant to be anchored in the posterior ilium, a few centimeters anterior to the PSIS (114). Contraindications to its use include comminuted or transforaminal sacral fractures, iliac wing fractures, and LC-type fractures $(32,115)$. Theoretically, the C clamp can be applied in the emergency department without fluoroscopy, however, it is advantageous to apply it in the operating room under fluoroscopic control, given that major complications, such as fracture displacement, perforation through the ileum, nerve injury, and hematoma formation can arise from inadvertent misplacement (116-118). An advantage of the C clamp is that it can rotate around its axis, allowing access to the abdomen and groin. The C clamp can also be used for anterior pelvic disruption, such as APC 2, when it is applied anteriorly. External fixation, either with formal half pins or by some form of temporary pelvic C-clamp, can be useful in providing pelvic stability (34), however, both devices provide limited control of the posterior pelvis. Richard and Tornetta (119) and Archdeacon and Hiratzka (120) described an alternative technique involving application of a C clamp at the greater trochanters (T-clamp). In a recent case series of 17 hemodynamically unstable patients requiring pelvic stabilization, the T-clamp was a safe and effective method for pelvic stabilization (121).

\section{INTERNAL FIXATION}

The continuum of management of hemodynamically unstable patients with PRI ranges from damage control to early total care. In the acute setting, when dealing with a patient with $\mathrm{HI}$ and an unstable pelvic fracture, most authors agree that proceeding with definitive fixation of the pelvic fracture is not advocated due to the time consuming nature of the procedure and inherent risk from extensile approaches, pre-disposing the patient to increased hemorrhage, acidosis, hypothermia, and coagulation disturbances $(122,123)$.

Nevertheless, there is some evidence that maximizing early fixation of PRIs may be advantageous, or at least, not deleterious to patients. In a review of 45 patients with unstable pelvic fractures, Enninghorst et al. (124) found that despite having initial worse shock parameters, the acute ORIF group did not differ from the staged ORIF group with respect to transfusion rates, mortality, ICU, and overall length of stay, concluding that acute internal fixation could be performed even in critically ill patients (124). Further support for timely intervention is provided by Vallier et al. (125) who found a complication rate of 12.4 vs. $19.7 \%$ in patients treated in $<24$ and $>24 \mathrm{~h}$ from injury, respectively, including less ARDS and pneumonia.

The anterior external fixator, as discussed, is an excellent tool for closing down the anterior aspect of the pelvic ring. An alternative to the anterior external fixator is the anterior subcutaneous internal fixator (INFIX), which consists of a metal rod passed subcutaneously and connected to two pedicle screws anchored in supra acetabular bone (126). It attempts to address the issues of pin tract infections, osteomyelitis, loosening, loss of reduction, difficulty of use in obese patients, and restriction of movement (126). However, complications of the technique include lateral femoral cutaneous nerve irritation, femoral nerve palsy, and heterotopic ossification $(127,128)$. While the INFIX has a role, it is likely less appropriate in the emergency setting, where a percutaneously applied anterior external fixator can rapidly and effectively reduce the anterior pelvic ring.

Due to concerns regarding the use of a C-clamp (116118 ), alternative methods of posterior ring fixation have been devised. In trained hands, acute percutaneous stabilization of the posterior pelvic ring is possible through the use of an iliosacral screw (anti-shock screw) (129). Familiarity with the technique and ability to execute rapidly is required. The risks of the technique include misplacement of the screw causing neurologic or vascular injury, inaccurate reduction, and mechanical failure of fixation (130). In cases where reduction is suboptimal, revision of fixation is possible once the physiologic status of the patient permits. 


\section{SPECIAL CONSIDERATIONS}

\section{Pediatric Pelvic Ring Injuries}

In general, pediatric PRIs fall under two camps, low energy pelvic avulsion fractures caused by lower energy mechanism such as during sports, and higher energy pelvic ring or acetabular disruptions (131). The skeletally immature pelvis is characterized by a greater portion of cartilaginous structures with variable rates of ossification. This factor, combined with flexibility through the tri-radiate cartilage and thicker periosteum lends itself to the greater elasticity of the pediatric pelvic ring which is thought to account for the lower incidence of PRIs in pediatric patients as compared to adult patients. However, when a ring disruption is present, it is often due to a high energy mechanism and suspicion must be raised for associated face/head $(49-58 \%$ of patients), thoracic (7-31\%), extremity (47-62\%), and abdominal (25\%) injuries (132-136). In terms of resuscitation of pediatric patients, the vasculature in children is more reactive and as such, early stages of hemorrhagic shock can be masked until patients are in the late stage. The initial evaluation is guided by the advanced pediatric life support protocols. Though the need for blood transfusion and angiographic intervention is similar between children and adults (131), the overall mortality in patients with pelvic fractures has been shown to be lower in children as compared to adults (5 vs. 17\%) with pelvic fracture associated hemorrhage occurring far less frequently in the pediatric population (137).

\section{Pelvic Ring Injuries During Pregnancy}

Despite the low prevalence of pregnancy amongst patients presenting with PRIs $(0.2-1.1 \%),(138,139)$ patients require immediate multidisciplinary care between obstetrics, general trauma surgeons, orthopedic traumatologists, anesthesia, and maternal-fetal medicine providers (140). Though maternal mortality in trauma is similar to mortality amongst non-pregnant patients, fetal mortality can be as high as $50-65 \%$ in the setting of severe blunt trauma and correlates with elevated injury severity score, maternal hemorrhage, coagulopathy, and abruptio placentae (140-142). Specifically with regard to hemodynamic instability, hypovolemic shock as with hemorrhage can decrease placental blood flow up to $20 \%$ contributing to higher rates of fetal demise (143). On initial evaluation, the primary goal remains restoration of the mother's physiology with resuscitative efforts, prompt diagnosis and initial treatment. The presence of vaginal blood must be evaluated for the presence of an open fracture, placenta previa, placental abruption, or labor (140). If a pelvic binder is to be used, it must not compress the gravid uterus and thereby lead to compression of the inferior vena cava. The resulting cardiac physiology changes associated with pregnancy, namely the increased plasma volume, may mask early signs of hypovolemic shock. Blood products must be Rh negative if the mother's blood type is unknown and a Kleiheir-Betke bloodtest or anti-HbF flow cytometry for circulating fetal hemoglobin may be considered to detect maternal-fetal hemorrhage (144, 145). Further, logrolling to the left lateral decubitus position is preferential to the straight supine position, especially later in pregnancy (140).

\section{Geriatric Patients}

The incidence of pelvic fractures has been shown to be higher in geriatric populations $(146,147)$. Geriatric patients have less physiologic reserve to respond to the stress of trauma, are more susceptible to clinically significant injuries, and have higher mortality, even in the setting of low energy mechanisms (148). Under triage remains a concern as up to $63 \%$ of patients with injury severity scores $>15$ have been shown to not meet the standard hemodynamic criteria for $\mathrm{HI}$ such as SBP $<90 \mathrm{mmHg}$ or heart rates above $120 \mathrm{bpm}$ (149). Systemic vascular resistance is often increased in the setting of baseline hypertension and heart rates may be blunted either due to ischemic heart conditions, a decreased response to catecholamines, or medications such as beta blockers. As such, modified criteria such as including age alone, SBP $<110 \mathrm{mmHg}$, and heart rate $>90 \mathrm{bpm}$ have been suggested as triaging criteria for elderly patients (149). Providers must maintain a high suspicion for shock in this patient cohort. Further, the presence of comorbid conditions such as heart failure or renal disease must be considered during the resuscitation as fluid overload may cause further morbidity. Given the above, serum lactate and base deficit may be better markers of resuscitation and end organ perfusion than vital signs in this patient population. With regards to PRIs and HI specifically, despite sustaining less severe fracture patterns, geriatric patients required greater rates of transfusion, undergo interventional angiography, and die despite aggressive resuscitation $(150,151)$. The increased bleeding in older patients has been postulated to be related to decreased vessel compliance seen with age and the decreased ability for vasospasm. In the setting of $\mathrm{HI}$, the presence of anticoagulants must be addressed with consideration given to anticoagulation reversal (152). The pre-injury anticoagulant and antiplatelet therapy is related with increased risk of post-traumatic hemorrhage (152, 153). Additionally, on an observational study about hip fractures pre-operative use of antiplatelet drugs was associated with an increased risk of transfusion and mortality and the use of nonvitamin $\mathrm{K}$ antagonist oral anticoagulant was associated with an increased risk of blood transfusion (154).

\section{CONCLUSIONS}

Pelvic ring injuries associated with hemodynamic instability require an expeditious evidence based and protocol driven approach to management. A pelvic binder should be applied as soon as hemodynamic instability is suspected followed by a thorough physical exam, a pelvic $x$-ray and in most cases a CT scan. Triage decisions are largely based on the patient's response to resuscitation and the results of imaging studies. The choice of taking the patient to the invasive radiology suite for pelvic artery embolization, the operating room for pelvic external fixation and possibly packing, or the intensive care unit should be the product of evidence-based protocols, surgeon experience, and institutional availability of the specific resources. Resuscitation efforts should consider specific patient populations and continue uninterrupted regardless of treatment or triage and until the patient is hemodynamically stable. 
Future research is needed to further identify the causes of hemodynamic instability in the trauma patient, an particularly the patient's response to resuscitation and the optimal timing of surgical intervention.

\section{REFERENCES}

1. American College of Surgeons. Advanced Trauma Life Support. 10th ed. Chicago, IL: American College of Surgeons (2018).

2. Perkins ZB, Maytham GD, Koers L, Bates P, Brohi K, Tai NRM. Impact on outcome of a targeted performance improvement programme in haemodynamically unstable patients with a pelvic fracture. Bone Joint $J$. (2014) 96-B:1090-7. doi: 10.1302/0301-620X.96B8.33383

3. Balogh Z, Caldwell E, Heetveld M, D'Amours S, Schlaphoff G, Harris I, et al. Institutional practice guidelines on management of pelvic fracturerelated hemodynamic instability: do they make a difference? J Trauma. (2005) 58:778-82. doi: 10.1097/01.TA.0000158251.40760.B2

4. Mutschler M, Nienaber U, Brockamp T, Wafaisade A, Fabian T, Paffrath T, et al. Renaissance of base deficit for the initial assessment of trauma patients: a base deficit-based classification for hypovolemic shock developed on data from 16,305 patients derived from the TraumaRegister DGU ${ }^{\circledR}$. Crit Care. (2013) 17:R42. doi: 10.1186/cc12555

5. Mutschler M, Nienaber U, Münzberg M, Wölfl C, Schoechl H, Paffrath T, et al. The shock index revisited-a fast guide to transfusion requirement? A retrospective analysis on 21,853 patients derived from the TraumaRegister DGU. Crit Care. (2013) 17:R172. doi: 10.1186/cc12851

6. Khurana B, Sheehan SE, Sodickson AD, Weaver MJ. Pelvic ring fractures: what the orthopedic surgeon wants to know. Radiographics. (2014) 34:131733. doi: $10.1148 / \mathrm{rg} .345135113$

7. Rossaint R, Bouillon B, Cerny V, Coats TJ, Duranteau J, Fernández-Mondéjar E, et al. Management of bleeding following major trauma: an updated European guideline. Crit Care. (2010) 14:R52. doi: 10.1186/cc8943

8. Porter JM, Ivatury RR. In search of the optimal end points of resuscitation in trauma patients: a review. J Trauma. (1998) 44:908-14. doi: 10.1097/00005373-199805000-00028

9. Brown JV, Yuan S. Traumatic injuries of the pelvis. Emerg Med Clin North Am. (2020) 38:125-42. doi: 10.1016/j.emc.2019.09.011

10. Duane TM, Tan BB, Golay D, Cole FJ, Weireter LJ, Britt LD. Blunt trauma and the role of routine pelvic radiographs: a prospective analysis. J Trauma. (2002) 53:463-8. doi: 10.1097/00005373-200209000-00011

11. Resnik CS, Stackhouse DJ, Shanmuganathan K, Young JW. Diagnosis of pelvic fractures in patients with acute pelvic trauma: efficacy of plain radiographs. Am J Roentgenol. (1992) 158:109-12. doi: 10.2214/ajr.158.1.1727335

12. Paydar S, Ghaffarpasand F, Foroughi M, Saberi A, Dehghankhalili M, Abbasi $\mathrm{H}$, et al. Role of routine pelvic radiography in initial evaluation of stable, high-energy, blunt trauma patients. Emerg Med J. (2013) 30:724-7. doi: 10.1136/emermed-2012-201445

13. Tile M. Acute pelvic fractures: II. Principles of management. J Am Acad Orthop Surg. (1996) 4:152-61. doi: 10.5435/00124635-199605000-00005

14. Tile M. Acute pelvic fractures: I. Causation and classification. J Am Acad Orthop Surg. (1996) 4:143-51. doi: 10.5435/00124635-199605000-00004

15. Young JW, Burgess AR, Brumback RJ, Poka A. Pelvic fractures: value of plain radiography in early assessment and management. Radiology. (1986) 160:445-51. doi: 10.1148/radiology.160.2.3726125

16. Meinberg EG, Agel J, Roberts CS, Karam MD, Kellam JF. Fracture and dislocation classification compendium-2018. J Orthop Trauma. (2018) 32(Suppl. 1):S1-170. doi: 10.1097/BOT.0000000000001063

17. Dalal SA, Burgess AR, Siegel JH, Young JW, Brumback RJ, Poka A, et al. Pelvic fracture in multiple trauma: classification by mechanism is key to pattern of organ injury, resuscitative requirements, and outcome. J Trauma. (1989) 29:981-1000; discussion 1000-2. doi: 10.1097/00005373-198907000-00012

18. Manson T, O’Toole RV, Whitney A, Duggan B, Sciadini M, Nascone J. Young-Burgess classification of pelvic ring fractures: does it predict

\section{AUTHOR CONTRIBUTIONS}

All authors participated in the literature search, writing, and editing of the manuscript.

mortality, transfusion requirements, and non-orthopaedic injuries? J Orthop Trauma. (2010) 24:603-9. doi: 10.1097/BOT.0b013e3181d3cb6b

19. Burgess AR, Eastridge BJ, Young JW, Ellison TS, Ellison PS, Poka A, et al. Pelvic ring disruptions: effective classification system and treatment protocols. J Trauma. (1990) 30:848-56. doi: 10.1097/00005373-199007000-00015

20. Magnussen RA, Tressler MA, Obremskey WT, Kregor PJ. Predicting blood loss in isolated pelvic and acetabular high-energy trauma. J Orthop Trauma. (2007) 21:603-7. doi: 10.1097/BOT.0b013e3181599c27

21. Starr AJ, Griffin DR, Reinert CM, Frawley WH, Walker J, Whitlock SN, et al. Pelvic ring disruptions: prediction of associated injuries, transfusion requirement, pelvic arteriography, complications, and mortality. J Orthop Trauma. (2002) 16:553-61. doi: 10.1097/00005131-200209000-00003

22. Whitbeck MG, Zwally HJ, Burgess AR. Innominosacral dissociation: mechanism of injury as a predictor of resuscitation requirements, morbidity, and mortality. J Orthop Trauma. (1997) 11:82-8. doi: 10.1097/00005131-199702000-00002

23. Dyer GSM, Vrahas MS. Review of the pathophysiology and acute management of haemorrhage in pelvic fracture. Injury. (2006) 37:602-13. doi: 10.1016/j.injury.2005.09.007

24. Kachlik D, Vobornik T, Dzupa V, Marvanova Z, Toupal O, Navara E, et al. Where and what arteries are most likely injured with pelvic fractures? The influence of localization, shape, and fracture dislocation on the arterial injury during pelvic fractures. Clin Anat. (2019) 32:682-8. doi: 10.1002/ca.23372

25. Falchi M, Rollandi GA. CT of pelvic fractures. Eur J Radiol. (2004) 50:96-105. doi: 10.1016/j.ejrad.2003.11.019

26. Blackmore CC, Jurkovich GJ, Linnau KF, Cummings P, Hoffer EK, Rivara FP. Assessment of volume of hemorrhage and outcome from pelvic fracture. Arch Surg. (2003) 138:504-8; discussion 508-9. doi: 10.1001/archsurg.138.5.504

27. Lee H-J, No H-K, Choi N-J, Sun H-W, Lee J-S, Jung Y-J, et al. The size of pelvic hematoma can be a predictive factor for angioembolization in hemodynamically unstable pelvic trauma. Ann Surg Treat Res. (2020) 98:146-52. doi: 10.4174/astr.2020.98.3.146

28. Michailidou M, Velmahos GC, van der Wilden GM, van der Wilden G, Alam HB, de Moya M, et al. "Blush" on trauma computed tomography: not as bad as we think! J Trauma Acute Care Surg. (2012) 73:580-4; discussion 584-6. doi: 10.1097/TA.0b013e318265cbd4

29. Omert LA, Salyer D, Dunham CM, Porter J, Silva A, Protetch J. Implications of the "contrast blush" finding on computed tomographic scan of the spleen in trauma. J Trauma. (2001) 51:272-7; discussion 277-8. doi: 10.1097/00005373-200108000-00008

30. Brown CVR, Kasotakis G, Wilcox A, Rhee P, Salim A, Demetriades D. Does pelvic hematoma on admission computed tomography predict active bleeding at angiography for pelvic fracture? Am Surg. (2005) 71:759-62. doi: $10.1177 / 000313480507100913$

31. Verbeek DO, Burgess AR. Importance of pelvic radiography for initial trauma assessment: an orthopedic perspective. $J$ Emerg Med. (2016) 50:852-8. doi: 10.1016/j.jemermed.2015. 03.048

32. Coccolini F, Stahel PF, Montori G, Biffl W, Horer TM, Catena F, et al. Pelvic trauma: WSES classification and guidelines. World J Emerg Surg. (2017) 12:5. doi: 10.1186/s13017-017-0117-6

33. Poole GV, Ward EF. Causes of mortality in patients with pelvic fractures. Orthopedics. (1994) 17:691-6.

34. Krieg JC, Mohr M, Ellis TJ, Simpson TS, Madey SM, Bottlang M. Emergent stabilization of pelvic ring injuries by controlled circumferential compression: a clinical trial. $J$ Trauma. (2005) 59:659-64. doi: 10.1097/01.ta.0000186544.06 101.11 
35. Croce MA, Magnotti LJ, Savage SA, Wood GW, Fabian TC. Emergent pelvic fixation in patients with exsanguinating pelvic fractures. $\mathrm{J} \mathrm{Am} \mathrm{Coll}$ Surg. (2007) 204:935-9; discussion 940-2. doi: 10.1016/j.jamcollsurg.2007. 01.059

36. Fu C-Y, Wu Y-T, Liao C-H, Kang S-C, Wang S-Y, Hsu Y-P, et al. Pelvic circumferential compression devices benefit patients with pelvic fractures who need transfers. Am J Emerg Med. (2013) 31:1432-6. doi: 10.1016/j.ajem.2013.06.044

37. Routt MLC, Falicov A, Woodhouse E, Schildhauer TA. Circumferential pelvic antishock sheeting: a temporary resuscitation aid. J Orthop Trauma. (2002) 16:45-8. doi: 10.1097/00005131-200201000-00010

38. Routt MLC, Falicov A, Woodhouse E, Schildhauer TA. Circumferential pelvic antishock sheeting: a temporary resuscitation aid. J Orthop Trauma. (2006) 20(Suppl. 1):S3-6. doi: 10.1097/01.bot.0000202386.86880.21

39. Langford JR, Burgess AR, Liporace FA, Haidukewych GJ. Pelvic fractures: part 1. Evaluation, classification, and resuscitation. J Am Acad Orthop Surg. (2013) 21:448-57. doi: 10.5435/JAAOS-21-08-448

40. Kellam JF. The role of external fixation in pelvic disruptions. Clin Orthop Relat Res. (1989) 241:66-82. doi: 10.1097/00003086-198904000-00009

41. Broos P, Vanderschot P, Craninx L, Rommens P. The operative treatment of unstable pelvic ring fractures. Int Surg. (1992) 77:303-8.

42. Bottlang M, Krieg JC, Mohr M, Simpson TS, Madey SM. Emergent management of pelvic ring fractures with use of circumferential compression. J Bone Joint Surg Am. (2002) 84-A(Suppl. 2):43-7. doi: 10.2106/00004623-200200002-00005

43. Chesser TJS, Cross AM, Ward AJ. The use of pelvic binders in the emergent management of potential pelvic trauma. Injury. (2012) 43:667-9. doi: 10.1016/j.injury.2012.04.003

44. Hedrick-Thompson JK. A review of pressure reduction device studies. J Vasc Nurs. (1992) 10:3-5. doi: 10.2307/4021363

45. Hilty MP, Behrendt I, Benneker LM, Martinolli L, Stoupis C, Buggy DJ, et al. Pelvic radiography in ATLS algorithms: a diminishing role? World J Emerg Surg. (2008) 3:11. doi: 10.1186/1749-7922-3-11

46. Cook RE, Keating JF, Gillespie I. The role of angiography in the management of haemorrhage from major fractures of the pelvis. J Bone Joint Surg Br. (2002) 84:178-82. doi: 10.1302/0301-620X.84B2.0840178

47. Tanizaki S, Maeda S, Matano H, Sera M, Nagai H, Ishida H. Time to pelvic embolization for hemodynamically unstable pelvic fractures may affect the survival for delays up to $60 \mathrm{~min}$. Injury. (2014) 45:738-41. doi: 10.1016/j.injury.2013.11.007

48. Stahel PF, Burlew CC, Moore EE. Current trends in the management of hemodynamically unstable pelvic ring injuries. Curr Opin Crit Care. (2017) 23:511-9. doi: 10.1097/MCC.0000000000000454

49. Cohen MJ, West M. Acute traumatic coagulopathy: from endogenous acute coagulopathy to systemic acquired coagulopathy and back. J Trauma. (2011) 70(Suppl. 5):S47-9. doi: 10.1097/TA.0b013e31821a5c24

50. Gando S, Nanzaki S, Kemmotsu O. Disseminated intravascular coagulation and sustained systemic inflammatory response syndrome predict organ dysfunctions after trauma: application of clinical decision analysis. Ann Surg. (1999) 229:121-7. doi: 10.1097/00000658-199901000-00016

51. Tieu BH, Holcomb JB, Schreiber MA. Coagulopathy: its pathophysiology and treatment in the injured patient. World J Surg. (2007) 31:1055-64. doi: 10.1007/s00268-006-0653-9

52. Giannoudi M, Harwood P. Damage control resuscitation: lessons learned. Eur J Trauma Emerg Surg. (2016) 42:273-82. doi: 10.1007/s00068-015-0628-3

53. Xiao W, Mindrinos MN, Seok J, Cuschieri J, Cuenca AG, Gao H, et al. A genomic storm in critically injured humans. J Exp Med. (2011) 208:2581-90. doi: $10.1084 /$ jem.20111354

54. Geeraedts LMG, Kaasjager HAH, van Vugt AB, Frölke JPM. Exsanguination in trauma: a review of diagnostics and treatment options. Injury. (2009) 40:11-20. doi: 10.1016/j.injury.2008.10.007

55. Rotondo MF, Schwab CW, McGonigal MD, Phillips GR, Fruchterman TM, Kauder DR, et al. "Damage control": an approach for improved survival in exsanguinating penetrating abdominal injury. J Trauma. (1993) 35:375-82; discussion 382-3. doi: 10.1097/00005373-199309000-00008

56. Pape H-C, Giannoudis PV, Krettek C, Trentz O. Timing of fixation of major fractures in blunt polytrauma: role of conventional indicators in clinical decision making. J Orthop Trauma. (2005) 19:551-62. doi: 10.1097/01.bot.0000161712.87129.80

57. Moore TA, Simske NM, Vallier HA. Fracture fixation in the polytrauma patient: markers that matter. Injury. (2020) 51(Suppl. 2):S10-4. doi: 10.1016/j.injury.2019.12.024

58. Cinat ME, Wallace WC, Nastanski F, West J, Sloan S, Ocariz J, et al. Improved survival following massive transfusion in patients who have undergone trauma. Arch Surg. (1999) 134:964-8; discussion 968-70. doi: 10.1001/archsurg.134.9.964

59. Geeraedts LMG, Demiral H, Schaap NP, Kamphuisen PW, Pompe JC, Frölke JPM. "Blind" transfusion of blood products in exsanguinating trauma patients. Resuscitation. (2007) 73:382-8. doi: 10.1016/j.resuscitation.2006.10.005

60. Holcomb JB, Wade CE, Michalek JE, Chisholm GB, Zarzabal LA, Schreiber $\mathrm{MA}$, et al. Increased plasma and platelet to red blood cell ratios improves outcome in 466 massively transfused civilian trauma patients. Ann Surg. (2008) 248:447-58. doi: 10.1097/SLA.0b013e318185a9ad

61. Vaslef SN, Knudsen NW, Neligan PJ, Sebastian MW. Massive transfusion exceeding 50 units of blood products in trauma patients. J Trauma. (2002) 53:291-5; discussion 295-6. doi: 10.1097/00005373-200208000-00017

62. Borgman MA, Spinella PC, Perkins JG, Grathwohl KW, Repine T, Beekley AC, et al. The ratio of blood products transfused affects mortality in patients receiving massive transfusions at a combat support hospital. J Trauma. (2007) 63:805-13. doi: 10.1097/TA.0b013e3181271ba3

63. Kornblith LZ, Howard BM, Cheung CK, Dayter Y, Pandey S, Busch MP, et al. The whole is greater than the sum of its parts: hemostatic profiles of whole blood variants. J Trauma Acute Care Surg. (2014) 77:818-27. doi: 10.1097/TA.0000000000000354

64. Gupta B, Garg N, Ramachandran R. Vasopressors: do they have any role in hemorrhagic shock? J Anaesthesiol Clin Pharmacol. (2017) 33:3. doi: 10.4103/0970-9185.202185

65. Cohen MJ, Kutcher M, Redick B, Nelson M, Call M, Knudson $\mathrm{MM}$, et al. Clinical and mechanistic drivers of acute traumatic coagulopathy. J Trauma Acute Care Surg. (2013) 75(1 Suppl. 1):S40-7. doi: 10.1097/TA.0b013e31828fa43d

66. Davenport R. Pathogenesis of acute traumatic coagulopathy. Transfusion. (2013) 53(Suppl. 1):23S-7S. doi: 10.1111/trf.12032

67. Fox N, Rajani RR, Bokhari F, Chiu WC, Kerwin A, Seamon MJ, et al. Evaluation and management of penetrating lower extremity arterial trauma: an Eastern Association for the Surgery of Trauma practice management guideline. J Trauma Acute Care Surg. (2012) 73(5 Suppl. 4):S315-20. doi: 10.1097/TA.0b013e31827018e4

68. Da Luz LT, Nascimento B, Shankarakutty AK, Rizoli S, Adhikari NK. Effect of thromboelastography $\left(\mathrm{TEG}^{\circledR}\right)$ and rotational thromboelastometry $\left(\right.$ ROTEM $^{\circledR}$ ) on diagnosis of coagulopathy, transfusion guidance and mortality in trauma: descriptive systematic review. Crit Care. (2014) 18:518. doi: 10.1186/s13054-014-0518-9

69. Gonzalez E, Moore EE, Moore HB, Chapman MP, Chin TL, Ghasabyan $A$, et al. Goal-directed hemostatic resuscitation of trauma-induced coagulopathy: a pragmatic randomized clinical trial comparing a viscoelastic assay to conventional coagulation assays. Ann Surg. (2016) 263:1051-9. doi: 10.1097/SLA.0000000000001608

70. Gonzalez E, Moore EE, Moore HB. Management of trauma-induced coagulopathy with thrombelastography. Crit Care Clin. (2017) 33:119-34. doi: 10.1016/j.ccc.2016.09.002

71. Mamczak CN, Maloney M, Fritz B, Boyer B, Thomas S, Evans E, et al. Thromboelastography in orthopaedic trauma acute pelvic fracture resuscitation: a descriptive pilot study. J Orthop Trauma. (2016) 30:299-305. doi: 10.1097/00005131-201606000-00003

72. Kaafarani HMA, Velmahos GC. Damage control resuscitation in trauma. Scand J Surg. (2014) 103:81-8. doi: 10.1177/1457496914524388

73. Huittinen VM, Slätis P. Postmortem angiography and dissection of the hypogastric artery in pelvic fractures. Surgery. (1973) 73:454-62.

74. Costantini TW, Coimbra R, Holcomb JB, Podbielski JM, Catalano R, Blackburn A, et al. Current management of hemorrhage from severe pelvic fractures: results of an American Association for the Surgery of Trauma multi-institutional trial. J Trauma Acute Care Surg. (2016) 80:717-23; discussion 723-5. doi: 10.1097/TA.0000000000001034 
75. Blondeau B, Orlando A, Jarvis S, Banton K, Berg GM, Patel N, et al. Variability in pelvic packing practices for hemodynamically unstable pelvic fractures at US level 1 trauma centers. Patient Saf Surg. (2019) 13:3. doi: 10.1186/s13037-019-0183-7

76. Athanasoulis CA, Duffield R, Shapiro JH. Angiography to assess pelvic vascular injury. $N$ Engl J Med. (1971) 284:1329. doi: 10.1056/NEJM197106102842316

77. Margolies MN, Ring EJ, Waltman AC, Kerr WS, Baum S. Arteriography in the management of hemorrhage from pelvic fractures. N Engl J Med. (1972) 287:317-21. doi: 10.1056/NEJM197208172870701

78. Matalon TS, Athanasoulis CA, Margolies MN, Waltman AC, Novelline RA, Greenfield AJ, et al. Hemorrhage with pelvic fractures: efficacy of transcatheter embolization. Am J Roentgenol. (1979) 133:859-64. doi: 10.2214/ajr.133.5.859

79. Vaidya R, Waldron J, Scott A, Nasr K. Angiography and embolization in the management of bleeding pelvic fractures. J Am Acad Orthop Surg. (2018) 26:e68-76. doi: 10.5435/JAAOS-D-16-00600

80. Salsamendi J, Quintana D, Kably I, Narayanan G. Special Considerations for Embolization in Trauma Cases. Endovascular Today. (2013). Available online at: https://evtoday.com/articles/2013-apr/special-considerations-forembolization-in-trauma-cases (accessed October 21, 2020).

81. Agolini SF, Shah K, Jaffe J, Newcomb J, Rhodes M, Reed JF. Arterial embolization is a rapid and effective technique for controlling pelvic fracture hemorrhage. J Trauma. (1997) 43:395-9. doi: 10.1097/00005373-199709000-00001

82. Fang J-F, Shih L-Y, Wong Y-C, Lin B-C, Hsu Y-P. Repeat transcatheter arterial embolization for the management of pelvic arterial hemorrhage. $J$ Trauma. (2009) 66:429-35. doi: 10.1097/TA.0b013e31817c969b

83. Hauschild O, Aghayev E, von Heyden J, Strohm PC, Culemann U, Pohlemann T, et al. Angioembolization for pelvic hemorrhage control: results from the German pelvic injury register. J Trauma Acute Care Surg. (2012) 73:679-84. doi: 10.1097/TA.0b013e318253b5ba

84. Matityahu A, Marmor M, Elson JK, Lieber C, Rogalski G, Lin C, et al. Acute complications of patients with pelvic fractures after pelvic angiographic embolization. Clin Orthop Relat Res. (2013) 471:2906-11. doi: $10.1007 /$ s1 1999-013-3119-z

85. Takahira N, Shindo M, Tanaka K, Nishimaki H, Ohwada T, Itoman M. Gluteal muscle necrosis following transcatheter angiographic embolisation for retroperitoneal haemorrhage associated with pelvic fracture. Injury. (2001) 32:27-32. doi: 10.1016/S0020-1383(00)00098-X

86. Velmahos GC, Chahwan S, Falabella A, Hanks SE, Demetriades D. Angiographic embolization for intraperitoneal and retroperitoneal injuries. World J Surg. (2000) 24:539-45. doi: 10.1007/s002689910087

87. El-Haj M, Bloom A, Mosheiff R, Liebergall M, Weil YA. Outcome of angiographic embolisation for unstable pelvic ring injuries: factors predicting success. Injury. (2013) 44:1750-5. doi: 10.1016/j.injury.2013.05.017

88. Katsura M, Yamazaki S, Fukuma S, Matsushima K, Yamashiro T, Fukuhara S. Comparison between laparotomy first versus angiographic embolization first in patients with pelvic fracture and hemoperitoneum: a nationwide observational study from the Japan Trauma Data Bank. Scand J Trauma Resusc Emerg Med. (2013) 21:82. doi: 10.1186/1757-7241-21-82

89. Kimbrell BJ, Velmahos GC, Chan LS, Demetriades D. Angiographic embolization for pelvic fractures in older patients. Arch Surg. (2004) 139:728-32; discussion 732-3. doi: 10.1001/archsurg.139.7.728

90. Salim A, Teixeira PGR, DuBose J, Ottochian M, Inaba K, Margulies DR, et al. Predictors of positive angiography in pelvic fractures: a prospective study. $J$ Am Coll Surg. (2008) 207:656-62. doi: 10.1016/j.jamcollsurg.2008.05.025

91. Schwartz DA, Medina M, Cotton BA, Rahbar E, Wade CE, Cohen AM, et al. Are we delivering two standards of care for pelvic trauma? Availability of angioembolization after hours and on weekends increases time to therapeutic intervention. J Trauma Acute Care Surg. (2014) 76:134-9. doi: 10.1097/TA.0b013e3182ab0cfc

92. Ierardi AM, Piacentino F, Fontana F, Petrillo M, Floridi C, Bacuzzi A, et al. The role of endovascular treatment of pelvic fracture bleeding in emergency settings. Eur Radiol. (2015) 25:1854-64. doi: 10.1007/s00330-015-3589-3

93. Eastridge BJ, Starr A, Minei JP, O’Keefe GE, Scalea TM. The importance of fracture pattern in guiding therapeutic decision-making in patients with hemorrhagic shock and pelvic ring disruptions. J Trauma. (2002) 53:446-50; discussion 450-1. doi: 10.1097/00005373-200209000-00009

94. Quinby WC. Pelvic fractures with hemorrhage. N Engl J Med. (1971) 284:668-9. doi: 10.1056/NEJM197103252841211

95. Pohlemann T, Gänsslen A, Bosch U, Tscherne H. The technique of packing for control of hemorrhage in complex pelvic fractures. Tech Orthop. (1994) 9:267-70. doi: 10.1097/00013611-199400940-00004

96. Cothren CC, Osborn PM, Moore EE, Morgan SJ, Johnson JL, Smith WR. Preperitonal pelvic packing for hemodynamically unstable pelvic fractures: a paradigm shift. J Trauma. (2007) 62:834-9; discussion 839-42. doi: 10.1097/TA.0b013e31803c7632

97. Burlew CC, Moore EE, Stahel PF, Geddes AE, Wagenaar AE, Pieracci FM, et al. Preperitoneal pelvic packing reduces mortality in patients with lifethreatening hemorrhage due to unstable pelvic fractures. J Trauma Acute Care Surg. (2017) 82:233-42. doi: 10.1097/TA.0000000000001324

98. Osborn PM, Smith WR, Moore EE, Cothren CC, Morgan SJ, Williams $\mathrm{AE}$, et al. Direct retroperitoneal pelvic packing versus pelvic angiography: a comparison of two management protocols for haemodynamically unstable pelvic fractures. Injury. (2009) 40:54-60. doi: 10.1016/j.injury.2008. 08.038

99. Li Q, Dong J, Yang Y, Wang G, Wang Y, Liu P, et al. Retroperitoneal packing or angioembolization for haemorrhage control of pelvic fracturesQuasi-randomized clinical trial of 56 haemodynamically unstable patients with injury severity score $\geq 33$. Injury. (2016) 47:395-401. doi: 10.1016/j.injury.2015.10.008

100. Prasarn ML, Horodyski M, Conrad B, Rubery PT, Dubose D, Small J, et al. Comparison of external fixation versus the trauma pelvic orthotic device on unstable pelvic injuries: a cadaveric study of stability. J Trauma Acute Care Surg. (2012) 72:1671-5. doi: 10.1097/TA.0b013e31824526a7

101. Smith W, Williams A, Agudelo J, Shannon M, Morgan S, Stahel P, et al. Early predictors of mortality in hemodynamically unstable pelvis fractures. $J$ Orthop Trauma. (2007) 21:31-7. doi: 10.1097/BOT.0b013e31802ea951

102. Wild JJ, Hanson GW, Tullos HS. Unstable fractures of the pelvis treated by external fixation. J Bone Joint Surg Am. (1982) 64:1010-20. doi: 10.2106/00004623-198264070-00007

103. Slätis P, Karaharju EO. External fixation of unstable pelvic fractures: experiences in 22 patients treated with a trapezoid compression frame. Clin Orthop Relat Res. (1980) 151:73-80. doi: 10.1097/00003086-198009000-00011

104. Burlew CC, Moore EE, Smith WR, Johnson JL, Biffl WL, Barnett $\mathrm{CC}$, et al. Preperitoneal pelvic packing/external fixation with secondary angioembolization: optimal care for life-threatening hemorrhage from unstable pelvic fractures. J Am Coll Surg. (2011) 212:628-35; discussion 635-7. doi: 10.1016/j.jamcollsurg.2010.12.020

105. Rommens PM, Hofmann A, Hessmann MH. Management of acute hemorrhage in pelvic trauma: an overview. Eur J Trauma Emerg Surg. (2010) 36:91-9. doi: 10.1007/s00068-010-1061-x

106. Ghanayem AJ, Stover MD, Goldstein JA, Bellon E, Wilber JH. Emergent treatment of pelvic fractures. Comparison of methods for stabilization. Clin Orthop Relat Res. (1995) 318:75-80.

107. Lee C, Sciadini M. The use of external fixation for the management of the unstable anterior pelvic ring. J Orthop Trauma. (2018) 32(Suppl. 6):S14-7. doi: 10.1097/BOT.0000000000001251

108. White CE, Hsu JR, Holcomb JB. Haemodynamically unstable pelvic fractures. Injury. (2009) 40:1023-30. doi: 10.1016/j.injury.2008.11.023

109. Mason WTM, Khan SN, James CL, Chesser TJS, Ward AJ. Complications of temporary and definitive external fixation of pelvic ring injuries. Injury. (2005) 36:599-604. doi: 10.1016/j.injury.2004.11.016

110. Gardner MJ, Kendoff D, Ostermeier S, Citak M, Hüfner T, Krettek C, et al. Sacroiliac joint compression using an anterior pelvic compressor: a mechanical study in synthetic bone. J Orthop Trauma. (2007) 21:435-41. doi: 10.1097/BOT.0b013e318126bb8e

111. Sellei RM, Schandelmaier P, Kobbe P, Knobe M, Pape H-C. Can a modified anterior external fixator provide posterior compression of AP compression type III pelvic injuries? Clin Orthop Relat Res. (2013) 471:28628. doi: 10.1007/s11999-013-2993-8

112. Ganz R, Krushell RJ, Jakob RP, Küffer J. The antishock pelvic clamp. Clin Orthop Relat Res. (1991) 267:71-8. doi: 10.1097/00003086-199106000-00009 
113. Heini PF, Witt J, Ganz R. The pelvic C-clamp for the emergency treatment of unstable pelvic ring injuries. A report on clinical experience of 30 cases. Injury. (1996) 27(Suppl. 1):S-A38-45. doi: 10.1016/S0020-1383(96)90110-2

114. Isler B, Ganz R. Classification of pelvic ring injuries. Injury. (1996) 27(Suppl. 1):S-A3-12. doi: 10.1016/S0020-1383(96)90105-9

115. Stahel PF, Mauffrey C, Smith WR, McKean J, Hao J, Burlew CC, et al. External fixation for acute pelvic ring injuries: decision making and technical options. J Trauma Acute Care Surg. (2013) 75:882-7. doi: 10.1097/TA.0b013e3182a9005f

116. Schütz M, Stöckle U, Hoffmann R, Südkamp N, Haas N. Clinical experience with two types of pelvic C-clamps for unstable pelvic ring injuries. Injury. (1996) 27(Suppl. 1):S-A46-50. doi: 10.1016/S0020-1383(96)90111-4

117. Pohlemann T, Braune C, Gänsslen A, Hüfner T, Partenheimer A. Pelvic emergency clamps: anatomic landmarks for a safe primary application. $J$ Orthop Trauma. (2004) 18:102-5. doi: 10.1097/00005131-200402000-00008

118. Bartlett C, Asprinio D, Louis S, Helfet D. Intrapelvic dislocation of the left hemipelvis as a complication of the pelvic "C" clamp: a case report and review. J Orthop Trauma. (1997) 11:540-2. doi: 10.1097/00005131-199710000-00014

119. Richard MJ, Tornetta P. Emergent management of APC-2 pelvic ring injuries with an anteriorly placed C-clamp. J Orthop Trauma. (2009) 23:322-6. doi: 10.1097/BOT.0b013e3181a196d5

120. Archdeacon MT, Hiratzka J. The trochanteric C-clamp for provisional pelvic stability. J Orthop Trauma. (2006) 20:47-51. doi: 10.1097/01.bot.0000175156.92743.db

121. Sepehri A, Sciadini MF, Nascone JW, Manson TT, O’Toole RV, Slobogean GP. Initial experience with the T-Clamp for temporary fixation of mechanically and hemodynamically unstable pelvic ring injuries. Injury. (2020) 51:699-704. doi: 10.1016/j.injury.2020. 01.030

122. Giannoudis PV. Surgical priorities in damage control in polytrauma. J Bone Joint Surg Br. (2003) 85:478-83. doi: 10.1302/0301-620X.85B4. 14217

123. Pape H-C, Giannoudis P, Krettek C. The timing of fracture treatment in polytrauma patients: relevance of damage control orthopedic surgery. Am J Surg. (2002) 183:622-9. doi: 10.1016/S0002-9610(02)0 0865-6

124. Enninghorst N, Toth L, King KL, McDougall D, Mackenzie S, Balogh ZJ. Acute definitive internal fixation of pelvic ring fractures in polytrauma patients: a feasible option. J Trauma. (2010) 68:935-41. doi: 10.1097/TA.0b013e3181d27b48

125. Vallier HA, Cureton BA, Ekstein C, Oldenburg FP, Wilber JH. Early definitive stabilization of unstable pelvis and acetabulum fractures reduces morbidity. J Trauma. (2010) 69:677-84. doi: 10.1097/TA.0b013e3181 e50914

126. Vaidya R, Martin AJ, Roth M, Tonnos F, Oliphant B, Carlson J. Midterm radiographic and functional outcomes of the anterior subcutaneous internal pelvic fixator (INFIX) for pelvic ring injuries. J Orthop Trauma. (2017) 31:252-9. doi: 10.1097/BOT.0000000000000781

127. Vaidya R, Kubiak EN, Bergin PF, Dombroski DG, Critchlow RJ, Sethi A, et al. Complications of anterior subcutaneous internal fixation for unstable pelvis fractures: a multicenter study trauma. Clin Orthop. (2012) 470:2124-31. doi: 10.1007/s11999-011-2 233-z

128. Hesse D, Kandmir U, Solberg B, Stroh A, Osgood G, Sems SA, et al. Femoral nerve palsy after pelvic fracture treated with INFIX: a case series. J Orthop Trauma. (2015) 29:138-43. doi: 10.1097/BOT.000000000000 0193

129. Gardner MJ, Chip Routt ML. The antishock iliosacral screw. J Orthop Trauma. (2010) 24:e86-89. doi: 10.1097/BOT.0b013e3181c $81 \mathrm{~d} 65$

130. Acker A, Perry ZH, Blum S, Shaked G, Korngreen A. Immediate percutaneous sacroiliac screw insertion for unstable pelvic fractures: is it safe enough? Eur J Trauma Emerg Surg. (2018) 44:163-9. doi: 10.1007/s00068-016-0654-9

131. Amorosa LF, Kloen P, Helfet DL. High-energy pediatric pelvic and acetabular fractures. Orthop Clin North Am. (2014) 45:483-500. doi: 10.1016/j.ocl.2014.06.009
132. Demetriades D, Karaiskakis M, Velmahos GC, Alo K, Murray J, Chan L. Pelvic fractures in pediatric and adult trauma patients: are they different injuries? J Trauma. (2003) 54:1146-51; discussion 1151. doi: 10.1097/01.TA.0000044352.00377.8F

133. Helfet DL, Koval KJ, Hissa EA, Patterson S, DiPasquale T, Sanders R. Intraoperative somatosensory evoked potential monitoring during acute pelvic fracture surgery. $J$ Orthop Trauma. (1995) 9:28-34. doi: 10.1097/00005131-199502000-0 0005

134. Lewallen LW, McIntosh AL, Sems SA. Pediatric pelvic ring injuries. Orthopedics. (2018) 41:e701-4. doi: 10.3928/01477447-20180806-03

135. Spiguel L, Glynn L, Liu D, Statter M. Pediatric pelvic fractures: a marker for injury severity. Am Surg. (2006) 72:481-4. doi: 10.1177/000313480607200604

136. de la Calva C, Jover N, Alonso J, Salom M. Pediatric pelvic fractures and differences compared with the adult population. Pediatr Emerg Care. (2018) 36:519-22. doi: 10.1097/PEC000000000000411

137. Ismail N, Bellemare JF, Mollitt DL, DiScala C, Koeppel B, Tepas JJ. Death from pelvic fracture: children are different. J Pediatr Surg. (1996) 31:82-5. doi: 10.1016/S0022-3468(96)90324-3

138. Pape HC, Pohlemann T, Gänsslen A, Simon R, Koch C, Tscherne H. Pelvic fractures in pregnant multiple trauma patients. J Orthop Trauma. (2000) 14:238-44. doi: 10.1097/00005131-200005000-00003

139. Almog G, Liebergall M, Tsafrir A, Barzilay Y, Mosheiff R. Management of pelvic fractures during pregnancy. Am J Orthop. (2007) 36:E153-9.

140. Yoo BJ. Pelvic trauma and the pregnant patient: a review of physiology, treatment risks, and options. Curr Trauma Rep. (2018) 4:225-32. doi: 10.1007/s40719-018-0136-0

141. Ali J, Yeo A, Gana TJ, McLellan BA. Predictors of fetal mortality in pregnant trauma patients. J Trauma. (1997) 42:782-5. doi: 10.1097/00005373-199705000-00005

142. Mattox KL, Goetzl L. Trauma in pregnancy. Crit Care Med. (2005) 33(Suppl. 10):S385-9. doi: 10.1097/01.CCM.0000182808.99433.55

143. Jain V, Chari R, Maslovitz S, Farine D, Maternal Fetal Medicine Committee, Bujold E, et al. Guidelines for the management of a pregnant trauma patient. J Obstet Gynaecol Can. (2015) 37:553-74. doi: 10.1016/S1701-2163(15)3 0232-2

144. Kim YA, Makar RS. Detection of fetomaternal hemorrhage. Am J Hematol. (2012) 87:417-23. doi: 10.1002/ajh.2 2255

145. Muench MV, Baschat AA, Reddy UM, Mighty HE, Weiner CP, Scalea $\mathrm{TM}$, et al. Kleihauer-betke testing is important in all cases of maternal trauma. J Trauma. (2004) 57:1094-8. doi: 10.1097/01.TA.0000096654.3 7009.B7

146. Clement ND, Court-Brown CM. Elderly pelvic fractures: the incidence is increasing and patient demographics can be used to predict the outcome. Eur J Orthop Surg Traumatol. (2014) 24:1431-7. doi: 10.1007/s00590-014-1439-7

147. Ragnarsson B, Jacobsson B. Epidemiology of pelvic fractures in a Swedish county. Acta Orthop Scand. (1992) 63:297-300. doi: 10.3109/1745367920915 4786

148. Jacobs DG. Special considerations in geriatric injury. Curr Opin Crit Care. (2003) 9:535-9. doi: 10.1097/00075198-200312000-0 0012

149. Demetriades D, Sava J, Alo K, Newton E, Velmahos GC, Murray JA, et al. Old age as a criterion for trauma team activation. J Trauma. (2001) 51:754-6; discussion 756-7. doi: 10.1097/00005373-200110000-0 0022

150. Henry SM, Pollak AN, Jones AL, Boswell S, Scalea TM. Pelvic fracture in geriatric patients: a distinct clinical entity. J Trauma. (2002) 53:15-20. doi: 10.1097/00005373-200207000-0 0004

151. O’brien DP, Luchette FA, Pereira SJ, Lim E, Seeskin CS, James L, et al. Pelvic fracture in the elderly is associated with increased mortality. Surgery. (2002) 132:710-4; discussion 714-5. doi: 10.1067/msy.2002. 127690

152. Calland JF, Ingraham AM, Martin N, Marshall GT, Schulman CI, Stapleton T, et al. Evaluation and management of geriatric trauma: an Eastern Association for the Surgery of Trauma practice management guideline. J Trauma Acute 
Care Surg. (2012) 73(5 Suppl. 4):S345-50. doi: 10.1097/TA.0b013e31827 0191f

153. Franko J, Kish KJ, O’Connell BG, Subramanian S, Yuschak JV. Advanced age and preinjury warfarin anticoagulation increase the risk of mortality after head trauma. J Trauma. (2006) 61:107-10. doi: 10.1097/01.ta.0000224220.8 9528.fc

154. Daugaard C, Pedersen AB, Kristensen NR, Johnsen SP. Preoperative antithrombotic therapy and risk of blood transfusion and mortality following hip fracture surgery: a Danish nationwide cohort study. Osteoporos Int. (2019) 30:583-91. doi: 10.1007/s00198-018-4 786-0
Conflict of Interest: The authors declare that the research was conducted in the absence of any commercial or financial relationships that could be construed as a potential conflict of interest.

Copyright (C) 2020 Marmor, El Naga, Barker, Matz, Stergiadou and Miclau. This is an open-access article distributed under the terms of the Creative Commons Attribution License (CC BY). The use, distribution or reproduction in other forums is permitted, provided the original author(s) and the copyright owner(s) are credited and that the original publication in this journal is cited, in accordance with accepted academic practice. No use, distribution or reproduction is permitted which does not comply with these terms. 